Niğde Ömer Halisdemir Üniversitesi Mühendislik Bilimleri Dergisi
Niğde Ömer Halisdemir University Journal of Engineering Sciences

\title{
Bir prototip kağıt kesme makinesi tasarımı
}

\section{Design of a prototype for paper cutting machine}

\author{
Hasan Demirtaş ${ }^{1, *}$ \\ ${ }^{1}$ Samsun Üniversitesi, Makine Mühendisliği Bölümü, 55080, Samsun, Türkiye
}

\begin{abstract}
Özet
Günümüzde en çok kullanılan kâğıt tipi olan A4 kağıdı, bünyesinde odun miktarı en az seviyede olan 1. Hamur kağıdı kullanılarak imal edilmektedir. A4 boyutu kâğıtlar ise büyük ebatlardaki ruloların enine ve boyuna kesilmesi ile elde edilmektedir. Türkiye'de ise bu tipte bir makinenin üretimi yapılmamaktadır. Bu çalışmada, büyük ebatlarda bir kağıt kesme makinesi için tasarlanmış olan bir prototip sunulmuştur. $\mathrm{Bu}$ prototip için farklı hızlarda hareket edebilen adım motorları kullanılmış ve polyamid merdaneler kullanılarak kağıdın yırtılmadan bir hat üzerinden diğerine transferi gerçekleştirilmiştir. Tasarlanan bir prototip kağıt kesme makinesi için karşılaşılan ve karşılaşılabilecek olan bazı sorunlar ele alınmış olup bu sorunların çözümlemesi için bazı çözümlemeler yapılmıştır. Kağıdın transferi sırasında mil eksenlerindeki kaçıklığın ve milleri taşıyan konstrüksiyonun düzgün bir şekilde monte edilmemesi halinde kağıdın düzgün bir şekilde kesilemediği tespit edilmiştir. Ayrıca kağıdı döndüren motorun hızının uygun bir oranda ayarlanamaması durumunda kağıdın gerilerek koptuğu gözlemlenmiştir.
\end{abstract}

Anahtar kelimeler: Kağıt, Prototip, Kağıt kesme makinesi

\section{Giriş}

Günümüzde ambalaj, eğitim, reklam vb. bir çok sektörde kullanılan kağıt, farklı ebatlarda üretilmektedir. Kağıdın temel malzemelerinden olan odun ve selüloz oranları kağıdın kalitesini belirleyen en önemli faktörlerdir. 3 farklı kalite olarak üretilen kağıdın hamur çeşitleri:

1. Hamur Kağıt: Bu hamur tipi haberleşme, eğitim gibi alanlarda yazıların daha okunaklı elde edilmesinden dolayı en çok tercih edilen hamur tipidir.

2. Hamur Kağıt: Bu hamur tipi genelde düşük kalite bask1 almak için kullanılmakta olup rengi tam beyaz değildir.

3. Hamur Kağıt: Saman kağıdı olarak bilinen bu kağıtlar düşük fiyatlıdır ancak kaliteli baskı yapılmadığından tercih edilmez.

İlk olarak 1799 yılında Louis-Nicolas Robert tarafindan tasarlanan kağıt yapma makinesi, sürekli olarak kağıt üretimi yapamamakta ve geliştirilmesi gerekmekteydi. Bu yüzden sürekli kağıdı üreten ilk makine 1822 yılında Bryan Donkin tarafından geliştirilmiştir [1]. Chen vd. [2] yaptıkları çalışmada bal peteği yapısına sahip ve paketleme işlemlerinde kullanılan karton kağıt türünü düzgün bir şekilde kesilebilmesi için sonlu elemanlar yöntemini

\begin{abstract}
A4 paper is the most widely used paper type that is produced by using wood-free writing $\&$ printing paper with the least amount of wood in its structure. A4 size paper is produced by cutting large and long rolls in width and length directions. The construction of this machine is not made in Turkey. In this study, a prototype designed for a paper cutting machine is presented. For this prototype, step motors are used that can be set at different speeds and polyamide rollers are used to transfer the paper from one line to another without tearing. Some problems that is encountered for the designed paper cutting machine are discussed and some analyses are made to solve these problems. It has been found that the misalignment of the shaft axes during the transfer of the paper and the not suitable construction of the shafts causes the non-uniform cutting of the paper. It is also observed that the speed of the motor must the paper adjusted at an appropriate rate, to avoid the stretch and break of paper.
\end{abstract}

Keywords: Paper, Prototype, Paper cutting machine

kullanmışlardır. Bununla birlikte, kağıdın enine düzgün kesilebilmesi için kontrol sistemleri ve algoritmalar geliştirilmiştir [3,4]. Ayrıca kesici bıçağı tutan merdanelerde Geneva mekanizması kullanılarak iyileştirmelerin yapıldığı belirtilmiştir [5-7]. Günümüzde kağıtlar farklı ebatlarda üretilmekte olup, kurumsal yazışmazlar, bilimsel yayınlar ve eğitim, öğretim sırasında en çok kullanılan kağıt tipi A4 kağıdıdır.

Tablo 1. Kağıt ebatları

\begin{tabular}{cll}
\hline $\begin{array}{c}\text { Kağıt } \\
\text { boyutu }\end{array}$ & Ölçüsü $(\mathrm{mm})$ & Ölçüsü (inç) \\
\hline A0 & $841 \times 1189$ & $33.13 \times 46.85$ \\
A1 & $594 \times 841$ & $23.40 \times 33.13$ \\
A2 & $420 \times 594$ & $16.55 \times 23.40$ \\
A3 & $297 \times 420$ & $11.70 \times 16.55$ \\
A4 & $210 \times 297$ & $8.27 \times 11.70$ \\
\hline
\end{tabular}

Farklı boyutlarda kâğıtların üretimi sırasında büyük rulolarda sarılı olarak bulunan kağıtlar, merdaneler yardımı ile kesici bıçaklara iletilmektedir. Bıçaklarda enine ve boyuna kesilen kağıtlar daha sonra bantlı sistemler yardımı ile adetli olarak paketlenmektedir. $\mathrm{Bu}$ işlem sırasında

\footnotetext{
* Sorumlu yazar / Corresponding author, e-posta / e-mail: hasan.demirtas@samsun.edu.tr (H. Demirtaş)

Geliş / Recieved: 22.09.2021 Kabul/ Accepted: 14.12.2021 Yayımlanma/Published: 14.01.2022

doi: 10.28948/ngmuh.998473
} 
ortamda bulunan toz, nem ve sıcaklık kağıdın kesim kalitesini etkileyen en önemli faktörlerdir.

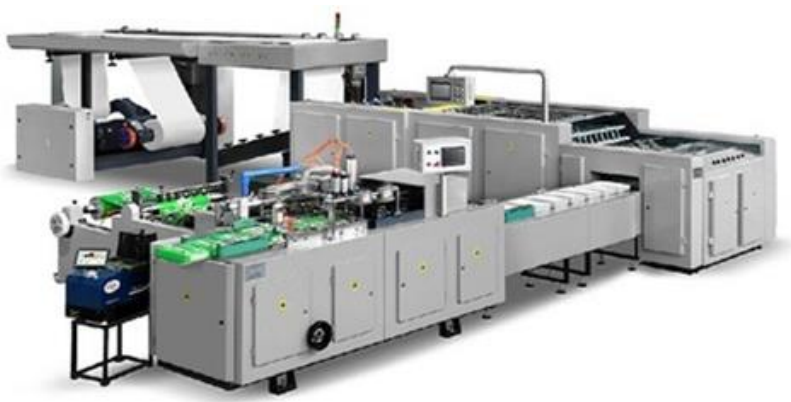

Şekil 1. Endüstriyel ölçekte bir A4 kağıt kesme makinesi [8]

Bu çalışmada, Türkiye'de henüz üretimi olmayan bir A4 kağıt kesme makinesi için bir prototip tasarlanmış ve bu prototipte karşılaşılan sorunlar ele alınmıştır. Bu sorunların çözümlemeleri yapılarak büyük ebatlarda bir A4 kağıt kesme makinesi için ön çalışmalar yapılmış ve sektörde ilgili alanlara çözüm önerileri sunularak verimliliğin arttırılması amaçlanmıştır.

\section{Materyal ve metot}

Şekil 2Hata! Başvuru kaynağı bulunamadı.'de tasarlanmış ve montajı yapılmış olan prototip kağıt kesme tezgahı gösterilmiştir. Bu tasarımda kağıt rulosu olarak 60 $\mathrm{mm}$ genişliğe ve $70 \mathrm{~mm}$ çapında 1 . kalite hamurdan üretilmiş olan kağıt kullanılmıştır. Rulo kâğıdının montajı ise hareketi sağlayan indüksiyonlu krom mile polyamid malzeme kullanılarak yapılmıştır. Ayrıca farklı uzunluklara sahip krom kaplı indüksiyonlu miller kullanılarak kâğıdın merdanelere iletirken yıpranmaması sağlanmıştır.

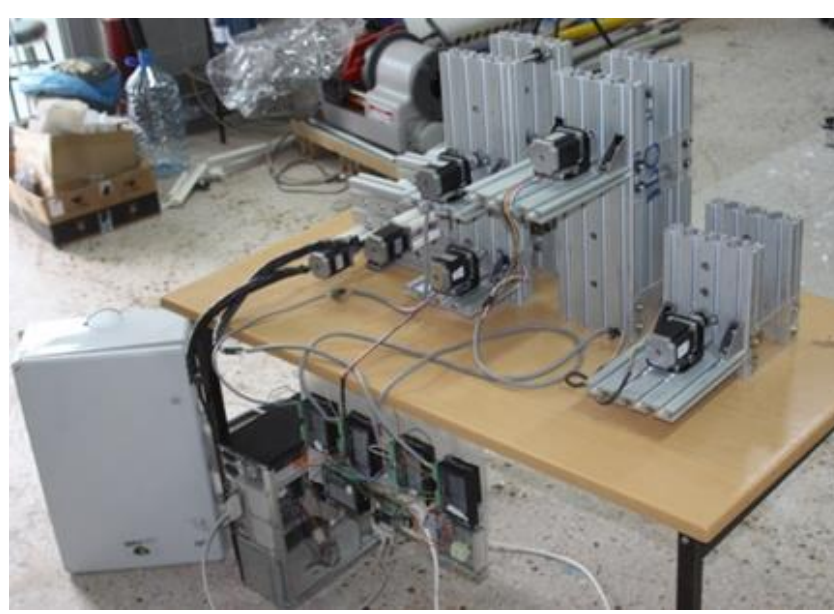

Şekil 2. Kağıt kesme makinesi prototipi

Kağıdın sıkıştırılarak iletilmesi için polyamid malzemeden üretilmiş merdaneler kullanılmış olup bu merdaneler ise krom kaplı indüksiyonlu millere sıkı geçme yöntemi uygulanarak monte edilmişlerdir. Kullanılan polyamid malzemeler Şekil 3 'te gösterilmiştir.

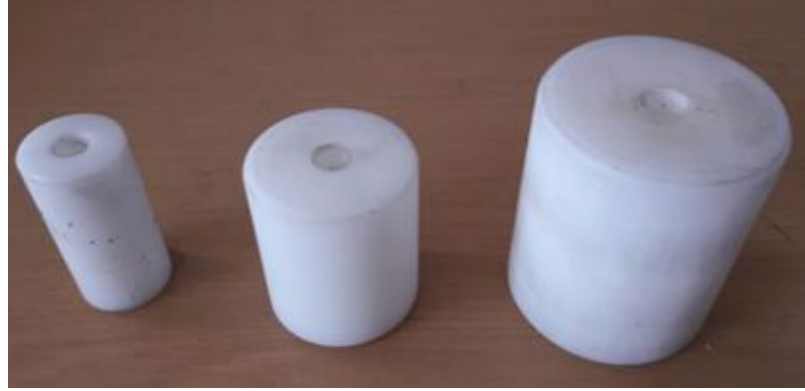

Şekil 3. Polyamid merdaneler

Merdanelerin, millerin ve kağıt rulonun rahat bir şekilde gövde içinde dönebilmesi için salyangoz tipte yataklı rulmanlar kullanılmış olup bu rulmanların ölçüleri ise Şekil 4 'te gösterilmiştir.
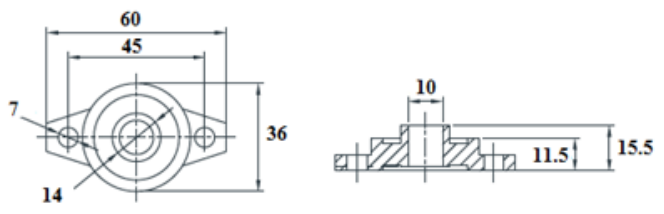

Şekil 4. Yataklı rulman

Yukarıda belirtilen parçaların bir konstrüksiyon üzerine hassas bir şekilde yerleştirilmesi ve işaretlemesi zaman ve maliyet gerektiren bir problem olarak karşımıza çıkmaktadır. $\mathrm{Bu}$ kapsamda konstrüksiyon malzemesi olarak hazır belli ölçülerde üretilmekte olan alüminyum sigma profiller kullanılmıştır. Profiller ise masaya ölçüleri uygun olacak şekilde köşe bağlantı elemanı yardımı ile yapılmıştır. Köşe bağlantı elemanın ölçüleri Şekil 5'te verilmiştir.

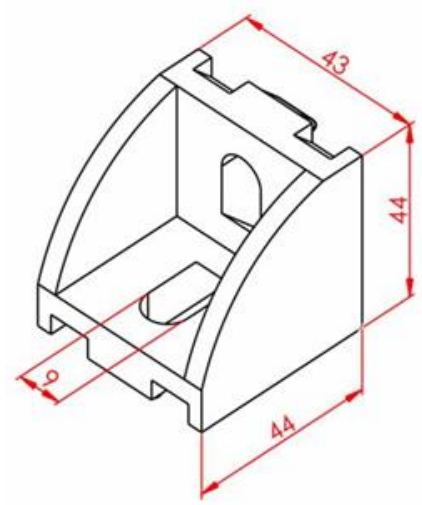

Şekil 5. Köşe bağlantı elemanı

Konstrüksiyon için kullanılan profillerde açılan ölçülü kanallar yardımı ile rulmanların montajı hassas ve kolay bir şekilde gerçekleştirilebilecektir. Ayrıca yumuşak bir malzeme olan alüminyum üzerinde işlem (delik delme, kesme vb.) yapmak diğer türde malzemelere göre daha kolaydır. $\mathrm{Bu}$ prototipte kullanılan alüminyum profiller mukavemet gerektiren makinelerin fiziksel yapıları için tercih edilmektedir. Bu tip profillerin teknik özellikleri Tablo 2'de, ölçüleri ise Şekil 6'da gösterilmiştir. 
Tablo 2. $45 * 180$ alüminyum profil teknik özellikleri [9]

\begin{tabular}{cccccc}
\hline $\begin{array}{c}\text { Diş Ebat } \\
(\mathrm{mm})\end{array}$ & Malzeme & $\mathrm{I}_{\mathrm{x}}\left(\mathrm{cm}^{4}\right)$ & $\mathrm{I}_{\mathrm{y}}\left(\mathrm{cm}^{4}\right)$ & $\mathrm{W}_{\mathrm{x}}\left(\mathrm{cm}^{3}\right)$ & $\mathrm{W}_{\mathrm{y}}\left(\mathrm{cm}^{3}\right)$ \\
\hline $45^{*} 180$ & 6063 & 747 & 56.7 & 83 & 25.2 \\
\hline
\end{tabular}

Kullanılan alüminyum levha üzerinde bulunan ve Şekil 5 'te gösterilen kanallar kullanılarak mil veya merdane eklenip, çıkarılabilmektedir. Böylece kâğıdın gerginliği değiştirilebilmektedir.
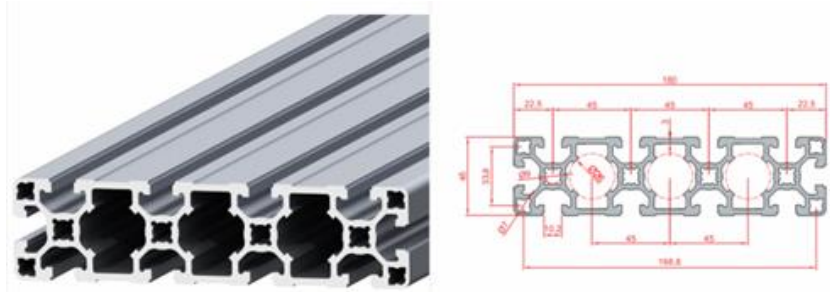

Şekil 6. Alüminyum profil [9]

Kağıdın hareketinin sağlanması için adım motorlar kullanılmıştır. Adım motorlar ise $210 \mathrm{~mm}$ uzunluğundaki indüksiyonlu mile hassas servo kaplinler ile bağlanmış ve milin eksen kaçıklığının önüne geçilmesi amaçlanmıştır. Adım motorların konstrüksiyona sabitlenmesi ise Şekil 7'de gösterildiği gibi flanşlar ve yüzey profilleri yardımı ile gerçekleştirilmiştir.

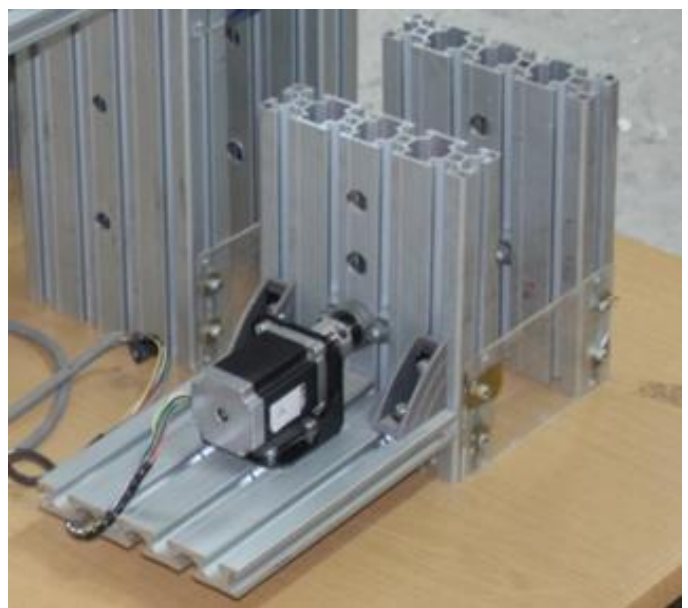

Şekil 7. Adım motorun konstrüksiyona montaj1

Adım motorlarda güç kaynağından akımı alıp sargılara ileten pinler bulunmaktadır. $\mathrm{Bu}$ pinler vasitasıly darbeli dalga boyları oluşturularak motorun kontrolü sağlanmaktadır. Ayrıca adım motoru, tam adım veya mikro adım yaparak hareketini sağlayan yöntemler vardır. Bu yöntemlerden birisi de motor sürücüsü kullanmaktır. Sunulan çalışmada beş adet motor ve bu motorların kontrolü için beş adet sürücü kullanılmıştır. Bu kapsamda her motor CNC tezgahının bir eksenini temsil edecek şekilde kontrol kartına bağlanmış olup bilgisayar üzerinden kontrolü sağlanmıştır. Böylece motorların dönüş hızları hem sürücü kullanılarak hem de bilgisayar üzerinden kontrol edilebilmektedir. Motor kontrol şeması Şekil 8'de, kontrol panosu ise Şekil 9'da gösterilmiştir.

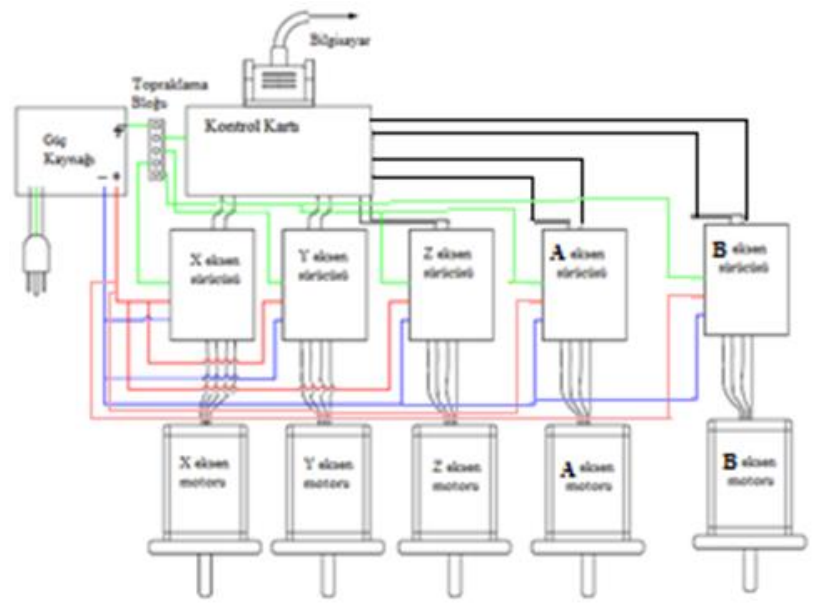

Şekil 8. Motor kontrol şeması

Kâğıt kesme makinesi ve bilgisayar arasındaki bilgi alışverişi ise paralel bağlantı kablosu (LPT) ile yapılmaktadır. Bilgi alışverişi için en kolay yollardan biri olan LPT, sadece tezgâhların bilgisayar ile bağlantısı için değil; aynı zamanda yazıcı bağlantıları, bilgisayarlar arası bilgi alışverişi, tarayıcı bağlantıları gibi birçok alanda kullanılabilmektedir.

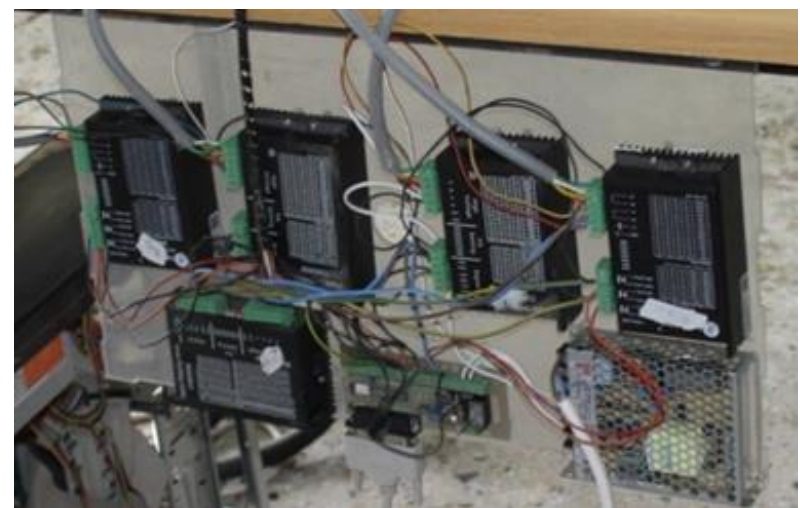

Şekil 9. Motor kontrol panosu

Kâğıtları kesmek için kullanılan bıçaklar özel ölçülerde bir firmaya imal ettirilmiştir. Dairesel bıçak ile kağıdın dikey doğrultuda kesilmesi, düz bıçak ile yatay doğrultuda kesilmesi sağlanmaktadır. Bıçakların fotoğrafları Şekil 10'da gösterilmiştir. Dairesel bıçak krom mil üzerine özel olarak tasarlanmış bir aparat yardımı ile monte edilmiş olup bir adım motor ile hareketi gerçekleştirilmektedir.

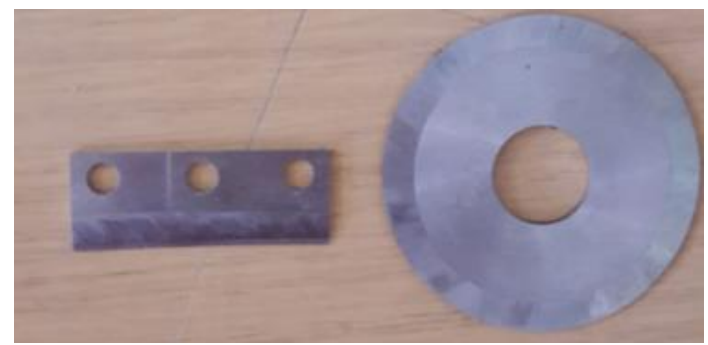

Şekil 10. Düz ve dairesel bıçaklar 
Tasarlanan prototip kağıt kesme makinesinde uygulanan deney şartları ise Tablo 3'te gösterilmiştir.

Tablo 3. Deney şartları

\begin{tabular}{cccc}
\hline $\begin{array}{c}\text { Deney } \\
\text { Şart1 }\end{array}$ & $\begin{array}{c}\text { Kesme } \\
\text { açıs }\end{array}$ & Mil sayısı & Mil dönme hızı (dev./dak.) \\
\hline 1 & 15 & 3 & 400 \\
\hline 2 & 15 & 4 & 500 \\
\hline 3 & 15 & 5 & 600 \\
\hline 4 & 15 & 6 & 700 \\
\hline 5 & 30 & 3 & 400 \\
\hline 6 & 30 & 4 & 500 \\
\hline 7 & 30 & 5 & 600 \\
\hline 8 & 30 & 6 & 700 \\
\hline 9 & 45 & 3 & 400 \\
\hline 10 & 45 & 4 & 500 \\
\hline 11 & 45 & 5 & 600 \\
\hline 12 & 45 & 6 & 700 \\
\hline 13 & 60 & 3 & 400 \\
\hline 14 & 60 & 4 & 600 \\
\hline 15 & 60 & 5 & 700 \\
\hline 16 & 60 & 6 &
\end{tabular}

Düz bıçak ise polyamid malzemeden üretilmiş bir aparat üzerine $15^{\circ}, 30^{\circ}, 45^{\circ}$ ve $60^{\circ}$ gibi farklı açılarla yerleştirilmiş böylece bıçak açısının kağıt kesildikten sonra bantlara iletilmesi sırasında etkisinin olup olmadığı incelenmiştir. Düz biçak için tasarlanan parçanın üç boyutlu modeli ve ölçüleri Şekil 11'de gösterilmiştir.
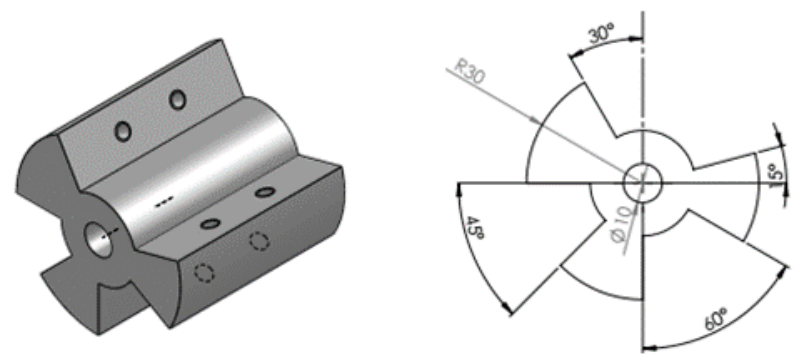

Şekil 11. Düz bıçak için tasarlanan aparat

Ayrıca düz bıçağın kağıdı kesebilmesi için bıçak ile çizgisel temas sağlayabilecek ve bıçağa zarar vermeyecek şekilde bir silindir parça yerleştirilmiştir. $\mathrm{Bu}$ silindir, rulmanlar yardımı ile serbest hareket edebilmekte böylece bıçağın hareketine etkisi bulunmamaktadır. Şekil 12'de düz bıçak ve silindirin konumlanma şematiği gösterilmiştir.

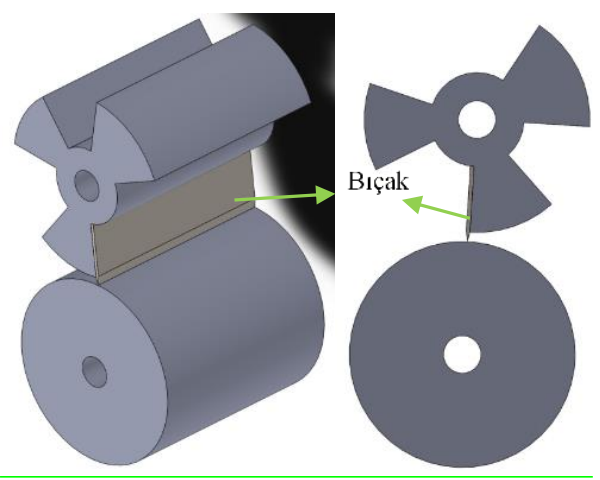

Şekil 12. Düz bıçak ve silindir arasında çizgisel teması gösteren şematik

\section{Bulgular ve tartışma}

Yapılan çalışmalar sonucunda ince ve hafif bir malzeme olan kağıdın rulodan kesim işlemine iletilmesi sırasında kağıt gerginliğini büyük bir öneme sahip olduğu görülmüştür. $\mathrm{Bu}$ kapsamda profil konstrüksiyon üzerine belirli mesafeler ve açılarla krom kaplı miller yerleştirilmiştir. Böylece kağıdın gerginliğinin arttırılması sağlanmıştır. Fakat yapılan çalışmalar göstermiştir ki kağıdın gerginliği için sadece mil yerleştirilmesi yeterli gelmemiş, bununla birlikte ruloyu ve merdaneleri hareket ettiren motorun dönüş hızının da büyük bir etkisi olduğu gözlenmiştir. Artan mil sayısı kağıdı hareket mesafesini arttırmış böylece merdane dönüş hızı ile rulo dönüş hızı arasındaki farkta artmıştır. Rulonun dönüş hızı merdanenin dönüş hızı ile aynı veya daha düşük olduğundan kağıt aşırı miktarda gerilmekte böylece kağıt yırtılmaktadır. Bu da mil sayısı ile kağıt rulo dönüş hızının ters orantılı olarak değiştiğini göstermektedir. Bununla birlikte rulo hızının aşırı arttırılması ise kağıdın gerginliğinin düşmesine bu ise kağıdın yönünde sapmalara neden olmaktadır. Böylece kağıt, kesme işlemi sırasında düzgün hareket etmemekte, kesim işlemi düzgün bir şekilde gerçekleştirilememektedir.

Kağıt kesme işleminde karşılaşılan bir diğer önemli sorun ise konstrüksiyona monte edilen millerin eksen kaçıklıklarıdır. Bu kapsamda kullanılan salyangoz tipte olan yataklama rulmanları içten dönmekte ve milde kaçıklıklara neden olmaktadır. Ekseninden kaçık olan miller kağıdın yönünde sapmalara ve kağıdın eşit bir şekilde kesilememesine neden olmaktadır. İşlemin bu şekilde devam etmesi durumunda ise kağıtta kopmalar oluşmaktadır.

Ayrıca merdane olarak kullanılan silindirlerde kağıt hareketi sıkışmanın düzgün bir şekilde gerçekleştirilemediği tespit edilmiştir. Bu yüzden merdaneler düz silindir yerine dozaj tipte merdaneler kullanılmıştır. Dozaj merdane ölçüleri Şekil 13'te gösterilmiştir.

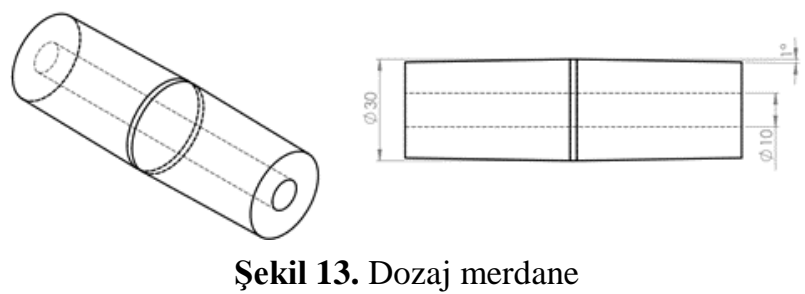

Bununla birlikte yaptığı hareket boyunca kağıdı kesen dairesel bıçağın hızının arttırılması ile bıçağın kağıdı kesme hızı artmaktadır. Böylece kağıdın millerden ve merdane üzerinden iletimi daha kolay hale gelmektedir. Ayrıca dairesel bıçak için yapılan aparatın düzgün bir şekilde bıçağ tutması ile kesim işleminin doğrultusundan sapmadan yapıldığı görülmüştür. Düz bıçaklarda ise kullanılan açılar arasından kağıdın konveyör bantlara iletimini en iyi şekilde sağlayan $30^{\circ}$ olduğu tespit edilmiştir. Bunun nedeni ise kağıdı ileten yüzey alanın en çok $30^{\circ}$ 'lik kısımda olmasıdır. Böylece kağıt iletim sistemden uzaklaşmadan iletim bandına taşınabilmektedir. 


\section{Sonuçlar}

$\mathrm{Bu}$ çalışmada bir A4 kağı kesme makinesinde karşılaşlabilecek sorunların tespiti ve çözüm yollarının oluşturulabilmesi için tasarlanmış olan bir prototip sunulmuştur. $\mathrm{Bu}$ prototipte karşılaşılan bazı sorunlar ve çözüm önerileri ise aşağıdaki gibi sıralanabilir;

- Kağıt gerginliği;

○ Mil sayısının arttırılması

- Motor hızının mil sayısına bağlı olarak arttırılmasi veya azaltılmas1

- Kağıdın düzgün bir şekilde iletilememesi

- Kullanılan mil ve merdanelerdeki eksen kaçıklıklarının giderilmesi

- Merdanelerde düz silindir yerine dozaj silindir kullanılması

- Kağıdın düzgün kesilememesi

○ Bıçak kesme hızının arttırılması

○ Düz bıçakların kesimi için çizgisel temaslı merdane yerleştirilmesi

Ayrıca bu çalışma sonucunda Türkiye'de henüz üretimi olmayan büyük ebatlarda bir A4 kağıt kesme makinesinin üretimine geçilmesi planlanmaktadır.

\section{Çıkar çatışması}

Yazarlar çıkar çatı̧̧ması olmadı̆̆ı̆ı beyan etmektedir.

Benzerlik oranı (iThenticate): $\% 4$

\section{Kaynaklar}

[1] R.H. Clapperton, The Paper-Making Machine. Pergamon Press, pp. 365. Londra, 1967.

[2] Q. Chen and Y. Lv, Design of paper cutter machine, 9th International Conference on Computer-Aided
Industrial Design and Conceptual Design, CAIDCD 2008, IEEE, sayfa 504-508, Kunming, Çin, 22-25 Kasım 2008

[3] M. Bebić, N. Rašić, S. Štatkić, L. Ristić, D. Jevtić, I. Mihailović and B. Jeftenić, Drives and control system for paper-board cross cutter, 15th International Power Electron. Motion Control Conference Expo, EPEPEMC 2012 ECCE Eur., sayfa: 1-8, Novi Sad., 4-6 Eylül 2012.

[4] H. Wu, N. Luo and C. Wang, Study on control strategy of the rotary synchronous fixed-length cutting system, Journal of Vibroengineering, 15(2), 713-725,2013.

[5] N. S. Jain, and A. Rai, Modification of the geneva paper cutting tool, International Journal of Innovations in Engineering and Technology, 11(3), 94-98, 2018. http://dx.doi.org/10.21172/ijiet.113.15

[6] A.S. Parmar, A. Singh, A. Pandey, K. Singh and M. Upadhyay, Intermittent paper cutting mechanism by giving feed through geneva wheel, International Research Journal of Engineering and Technology, 4(5), 1454-1456, 2017.

[7] H. V. Sunil, A. Yadav, L. Shivu and S. Choudri, Automatic paper cutting machine using geneva mechanism, International Journal of Latest Engineering Research and Applications, 2(5), 38-45, 2017.

[8] A4 kağıt kesme makinesi, https://www.indiamart.com/proddetail/a4-papercutting-machine-0356196891.html/, Erişim tarihi 23 Ağustos 2019.

[9] Sigma profil teknik özellikleri, https://www.doguskalip.com.tr/Urun/45x180-sigmaprofil/1109, Erişim tarihi 21 Eylül 2021. 